\title{
Work in Progress - An investigation into the effect of an institutional honor code policy on academic behavior
}

\author{
Donald Carpenter ${ }^{1}$, Trevor Harding ${ }^{2}$, Cynthia Finelli $^{3}$, and Matthew Mayhew ${ }^{4}$
}

\begin{abstract}
Research indicates significant cheating at institutions of higher learning; however, evidence indicates that a well-designed and clearly-communicated campus honor code might have a mitigating effect. This is the impetus behind the implementation of an Academic Honor Code Policy at a private university beginning in the fall of 2004. This situation presented a unique opportunity to investigate the potential of an academic honor code to change the culture and behavior at a university. This investigation will involve conducting a longitudinal study on the academic habits of students as they progress through the curriculum and include students whose academic careers began under a different academic dishonesty policy. The presentation will describe the development and implementation of the honor code policy; details of the investigation including research questions being posed, survey development, and study protocols; and results from the first year of the study.
\end{abstract}

Index Terms - academic integrity, cheating, honor codes

\section{INTRODUCTION}

Research has shown that more than $70 \%$ of all students have reported one or more instances of cheating as undergraduates. For example, McCabe [1] collected data from 1,946 undergraduates at 16 highly selective institutions and reported that percentages of students who self reported engaging any type of cheating on a differed significantly by college major: business $(91 \%)$, engineering $(82 \%)$, social sciences $(73 \%)$, and natural sciences $(71 \%)$. However, evidence indicates that a well-designed and clearly-communicated campus honor code might have a mitigating effect on cheating. This is the impetus behind the implementation of an Academic Honor Code Policy at a small private university beginning in the fall of 2004.

The introduction of a new honor code presented a unique opportunity to investigate the potential to change the culture and behavior of students and faculty in a university setting. Previous research primarily focused on comparing honor code institutions to institutions without an honor code [2]. This investigation will involve conducting a longitudinal study on the academic habits of students as they progress through the curriculum and include students whose academic careers began under a different academic dishonesty policy. Finally, a key component of any honor code policy is faculty support for the policy. Therefore, the impact the Honor Code has on faculty actions and opinion regarding academic dishonesty on campus will also be determined by surveying faculty. This paper will describe the development and implementation of the honor code policy; details of the investigation including research questions being posed, survey development, and study protocols; and a discussion of project progress.

\section{HoNOR CODE POLICY}

One of the most important aspects of reducing cheating is to ensure that faculty and students understand the values and expectations of the institution. The institution's policy of academic integrity must reflect these values and be actively promoted by the administration [3]. Simply discussing the institution's policy and the penalties associated with cheating has been shown to be ineffective [4,5]. A preferable approach is to increase the understanding of what constitutes cheating and the communication about academic integrity between students and faculty.

One seemingly effective method is the adoption of an Honor Code Policy. Schools with well designed, and communicated, honor codes are known to have lower rates of cheating $[4,6]$. However, their greatest weakness seems to be that few faculty actually use them for dealing with cases of academic dishonesty, despite institutional requirements to do so.

The Honor Code Policy implemented at the institution in question is a component of the recently revised Student Code of Conduct implemented by the Dean of Students and Provost's Office. The Code of Conduct and Honor Code Policy are meant to address the basic core values of the institution and underscores the commitment of creating an academic community that values both individual and collaborative efforts while promoting student learning. The Honor Code Policy is described in a nine-page booklet that is

\footnotetext{
${ }^{1}$ Donald D. Carpenter, Assistant Professor, Civil Engineering Department, Lawrence Technological University, carpenter@1tu.edu

${ }^{2}$ Trevor Harding, Associate Professor, Manufacturing Engineering, Kettering University, tharding@kettering.edu

${ }^{3}$ Cynthia Finelli, Managing Director of the Center for Research on Learning and Teaching North, University of Michigan, cfinelli@umich.edu

${ }^{4}$ Matthew Mayhew, Director of Institutional Research, University of North Carolina - Wilmington, mmayhew@uncw.edu
} 
distributed to all incoming students and was mailed to existing students prior to its implementation in the fall of 2004. The booklet defines what constitutes an offense of the code and gives numerous examples of each; the responsibilities of each component of the university community including students, faculty, and the administration; the adjudication and appeals process; and finally the student pledge which reads "I have neither given nor received unauthorized aid in completing this work, nor have I presented someone else's work as my own." Students are required to write and sign the pledge on each submitted assignment.

\section{Project GoALS AND RESEARCH QUESTIONS}

The goal of this research project is to evaluate the effect an Honor Code Policy has on culture of academic integrity at the institution. The evaluation consists of conducting a longitudinal study on the academic behaviors of students as they matriculate through the curriculum. In addition, incoming students will be surveyed about their high school habits with regards to cheating. It has been found that previous behavior is a predictor of college cheating behavior so it is necessary to know what the students prior experiences are and if an Honor Code impacts their decision making process. Finally, a key component of any Honor Code policy is faculty support for the policy. Therefore, the impact the Honor Code has on faculty actions and opinion regarding academic dishonesty on campus also needs to be determined through a separate survey.

The research questions associated with the study include:

1) Does the presence of an Academic Honor Code reduce the overall level of cheating on campus over time?

2) Does the influence of an Academic Honor Code on behavior and attitude vary between traditional and nontraditional students? Transfer vs. Non-transfer? Freshman vs. Upper Division?

3) Are faculty implementing the mechanisms associated with the Academic Honor Code and enforcing penalties associated with violations?

4) Does the presence of an Academic Honor Code have an impact on the culture of the institution, specifically with respect to academic integrity, character development, and leadership?

\section{SURVEY DESIGN AND ADMINISTRATION}

The survey was designed specifically to provide answers to the research questions listed above. The institution currently does not have an institutional review board (IRB) to evaluate research utilizing human subjects. In lieu of an IRB, the Provost's Office and the Dean of Students approved the surveys and associated administering protocols. In addition, protocols utilized during this project were based on those utilized by the authors during other research projects, which did receive IRB approval from other institutions.

The primary instrument of the study is a four-page survey that contains 93 questions subdivided into 5 parts. Part 1 measures how often a student conducted a stated act in the previous semester. Part 2 indicates how the students evaluate certain cheating behaviors on a descriptive scale from Good to Bad. Parts 3 and 4 measure the level of student agreement about statements that relate to the Honor Code and the culture at the institution. Part 5 contains demographic information.

Approximately 500 surveys were administered to a sample of junior and senior level students early in the fall semester of 2004 with 423 completing the survey $(85 \%$ response rate). The data collected in the fall of 2004 will provide a baseline for student behavior prior to the implementation of the Honor Code Policy. In the spring of 2005, a sample of approximately 250 first year students representing the Class of 2008 was surveyed with 169 students completing the survey ( $68 \%$ response rate). In both cases, the surveys were distributed in classes and un-proctored; similar to end of term course evaluations. The responses are completely anonymous and students were informed of their rights as participants prior to survey distribution. The entire student body will be sampled in the spring of 2006, 2007, and 2008. This series of cross-sectional measurements will yield a four-year record of student academic integrity and allow the evaluation of the impact of an Honor Code Policy on student behavior.

\section{DISCUSSION}

The surveys have been scanned and frequency tables of student responses generated. Detailed statistical analysis has not yet been performed and no attempt to answer the research questions has been made as of May of 2005. Results and preliminary analysis will be presented in October at the conference.

The other aspect of this project is faculty behavior associated with the Honor Code Policy. In order to promote a culture of academic integrity, faculty need to communicate and enforce the academic policies of the University. Both full-time and adjunct faculty will be surveyed in summer of 2005 to determine their adherence to the policy and their overall impression of the effectiveness of the Honor Code Policy.

\section{REFERENCES}

1. McCabe, D.L. "Classroom cheating among natural science and engineering majors." Science and Engineering Ethics, 3, 433-445, 1997.

2. McCabe, D., Trevino, L.K., and Butterfield, K.D., "Academic Integrity in Honor Code and Non-Honor Code Environments: A qualitative investigation," Journal of Higher Education. 70(2), pp 211-234, 1999.

3. Hall, T. and Kuh, G.D., "Honor Among Students: Academic integrity and honor codes at state-assisted universities," NASPA Journal, 36(1) pp2-18, 1998.

4. Cochran, J.K., Chamlin, M.B., Wood, P.B. and Sellers, C.S., "Shame, Embarrassment, and Formal Sanction Threats: Extending the deterrence/rational choice model to academic dishonesty," Sociological Inquiry, 69(1), 1999, 91-105.

5. Roth, N.L. and McCabe, D.L.,."Communication Strategies for Adressing Academic Dishonesty," Journal of College Student Development, 36(6), pp 531-541, 1995.

6. McCabe, D. and Drinan, P., "Toward a Culture of Academic Integrity," Chronicle of Higher Education, 46(8), 1999.

October 19 - 22, 2005, Indianapolis, IN 